\title{
The correlative behavior of sandbars and shoreline along Sulina - Sf. Gheorghe beaches (Danube Delta Coast)
}

\author{
Florin TĂTUI $^{1 *}$ \\ ${ }^{1}$ Faculty of Geography, University of Bucharest, Romania \\ Received 20 October 2016; Revised 6 November 2016; Accepted 25 November 2016 \\ *Correspondence to: Florin TĂTUI, e-mail: florin.tatui@geo.unibuc.ro
}

\begin{abstract}
Longshore sandbars along wave-dominated sandy beaches are important for beach-dune system protection during storms. Our analysis is based on 6 years of seasonal and annual bathymetric surveys along $16 \mathrm{~km}$ of erosive, stable and accumulative low-lying non-tidal beaches northward of Sf. Gheorghe arm mouth (Danube Delta - Romanian Black Sea coast). Our results show significant correlations established between longshore sandbar crest positions and morphology with more intense coupling between the inner and outer sandbar sub-systems during high-energy conditions and more frequent along the northern erosive sector in comparison with the southern/central accumulative/stable ones. There is a good connection between the long-term shoreline mobility and sandbars offshore migration rates along different sectors of the study area, with faster sandbars movement and shorter cycle return periods along the northern erosive sector in comparison with the central (stable) and southern (accretionary) sectors. The longshore variations of the nearshore slope are the main driver of the relationship between long-term sandbars dynamics and shoreline variability along the study site.
\end{abstract}

KEYWORDS

longshore sandbars; offshore migration; bar migration cycle; shoreline dynamics; sediment transport

\section{Introduction}

Sandbars are underwater sandy ridges parallel to the shoreline that characterize many wavedominated beaches, affecting surfzone circulation and beach morphology and behaviour. Surfzone sandbars are some of the most intriguing, dynamical and complex morphological features of the coastal area. They develop two-dimensional (2D), alongshore- uniform or three-dimensional 
(3D), cross-shore varying geometries, each of them with specific patterns and behaviour. The international literature contains multiple references regarding the coupling between sandbars along different coastal environments and sandbar systems. The apparent coupled (Sonu, 1973; Van Enckevort and Wijnberg, 1999; Castelle et al., 2007; Ruessink et al., 2007; Quartel, 2009; Almar et al., 2010; Price et al., 2011) and non-coupled ((Hom-ma and Sonu, 1962; Bowman and Goldsmith, 1983) behaviour in $3 \mathrm{D}$ patterns of double sandbar systems was considered as reminiscent of the relationship between inner bar patterns and shoreline dynamics (Short, 1999; Coco et al., 2005; Thornton et al., 2007). Castelle et al. (2010) successfully simulated the coupling patterns observed in the field inside a crescentic double-sandbar system, showing that there is a morphological coupling between the outer bar geometry and the inner-bar rip channel development through the positive feedback between flow, sediment transport and the evolving morphology. This morphological coupling in multiple sandbar systems was reviewed by Price and Ruessink (2013) and Price et al. (2014). The shoreline - sandbars coupling was found to be related to the reduced separation between the inner sandbar and the shoreline (van de Lageweg et al., 2013), while the alongshore differences in outer bar behaviour influences the inner bar state and sensitivity of bar and beach profile (Gervais et al., 2013).

Rozynski (2003) found that, along a non-tidal four-barred Polish coastal site, there is a strong correlation between sandbars movement, the outer bars behaviour controlling the long-term evolution of the inner bars (with more than 60\%). On the Danube Delta coast, first information regarding the sedimentary exchanges and linkages between inner sandbar and shoreline were presented by Vespremeanu-Stroe (2001, 2007). Despite the relative high amount of information in the international literature, the factors and processes involved in the correlated behaviour of multi-barred systems (in connection or not to the shoreline) are not entirely and properly understood and further investigations should be done on different coastal environments in order to fully solve this gap. The aim of the current study is to analyse whether exists a coupling of sandbars and shoreline (taken individually and together) during their long-term cross-shore behaviour along a deltaic double/triplebarred non-tidal coast.

\section{Study area}

The study site is represented by the interdistributary Sulina - Sf. Gheorghe beach, Danube Delta, Romanian Black Sea coast (Fig. 1A, B). It is a virtually non-tidal environment, characterised by medium-wave conditions $\left(H_{s, 0}=1.43 \mathrm{~m} ; \mathrm{T}_{0}=5.5 \mathrm{~s}\right)$. Predominant and most energetic winds and waves are coming from $\mathrm{N}$ to $\mathrm{NE}$ directions (Fig. 1C). The nearshore is composed of predominantly quartz sand with an average median grain size of the shoreface of d50 $200 \mu \mathrm{m}$ (Fig. 1D).

The upper shoreface slope is gradually decreasing from $0.45-0.5 \mathrm{deg}$ along the northern study site (P8 - P18 profiles in Fig. 1B) to 0.35-0.4 deg along the central (P3 - P7) and southern sectors (P1 - P2) of the study site (Tătui and VespremeanuStroe, 2016). Following beach characteristics (width, slope, particle size), the northern part of the study site presents intermediate conditions (narrower beaches, higher slopes, coarser sediments) and erosive character, whereas the central and southern parts have a dissipative behaviour and show stable to advancing shoreline dynamics (Tătui et al., 2016). The upper shoreface of these erosive, stable and accretionary sectors presents two-three longshore sandbars, parallel with the shoreline, quasi-linear in shape, with no apparent 3D morphology. They experience significant intra-site variability expressed by narrow and steep bars (with low volumes) that migrate fast (migration rates of $43 \mathrm{~m} / \mathrm{yr}$ and corresponding cycle return periods of 3 years) over the narrow bar zone along the erosive northern sector and wide, flat bars (with high volumes) with slow migration (migration rates of $25 \mathrm{~m} / \mathrm{yr}$ and cycle return periods of 5.5 years) over the very large bar zone along the accumulative southern sector (Tătui et al., 2016). 

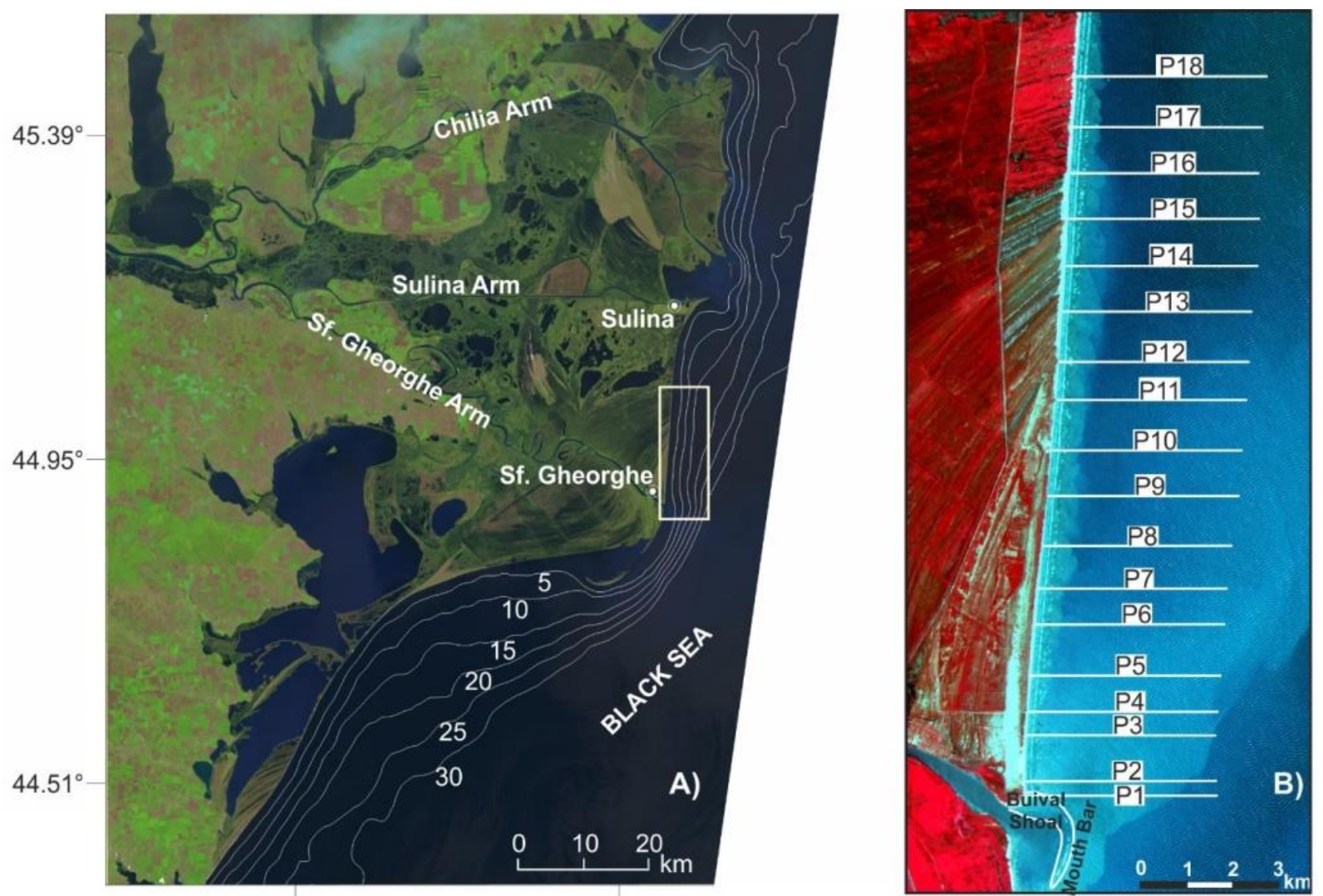

$28.89^{\circ}$

$29.56^{\circ}$
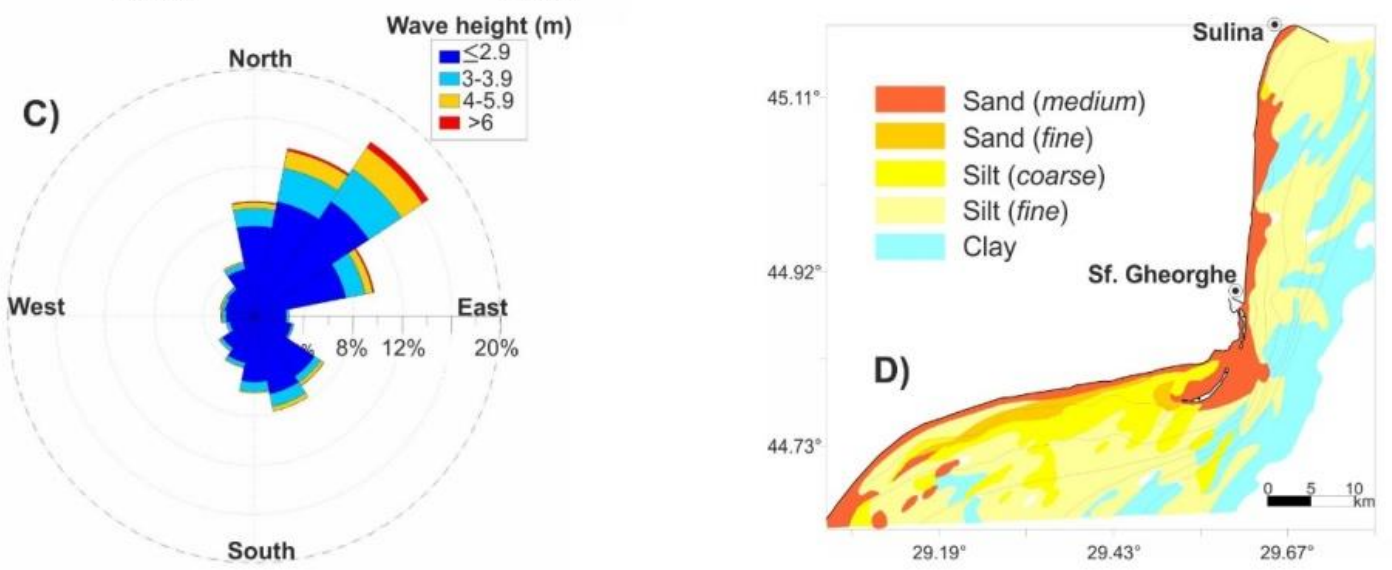

Figure 1 (A) The Danube Delta, Romanian Black Sea coast; (B) Location of the study site, as indicated by the white rectangle (P1 - P18 represent the cross-shore bathymetric profile used in the study); (C) Storm wave rose diagram (above $1.6 \mathrm{~m}$ ); (D) Sedimentological map of the study area (modified after GEOECOMAR, 1995)

\section{Data and methods}

Our dataset covers 6 years (September 2003 October 2009) of seasonal (especially spring and autumn) to annual bathymetric surveys (from shoreline to water depths of about $20 \mathrm{~m}$ ) along 18 cross-shore profiles, relatively equally spaced on 16 $\mathrm{km}$ northward from Sf. Gheorghe arm mouth (Fig. 1B), profiled with a Garmin echo-sounder. The resulting database comprises 5 to 15 temporal observations for each cross-shore profile. Based on the methodology described in Ruessink and Kroon (1994) and Grunnet and Hoekstra (2004), we extracted a number of simple morphometric 
parameters (bar crest position and depth; sandbar height, width and volume - Fig. 2) for each profile, as detailed in Tătui et al. (2011, 2016). The database was first reduced to a perturbation data set (containing residual profiles) by subtracting from each measured profile the smoothed mean profile for each longshore position. The mean profile was obtained by averaging all temporal measurements for each cross-shore position along the profile and was further smoothed (fitted profile in Fig. 2) using a low-step 5th-order Butterworth filter with a $200 \mathrm{~m}$ cut-off wave length (Ruessink et al., 2003; Grunnet and Hoekstra, 2004).

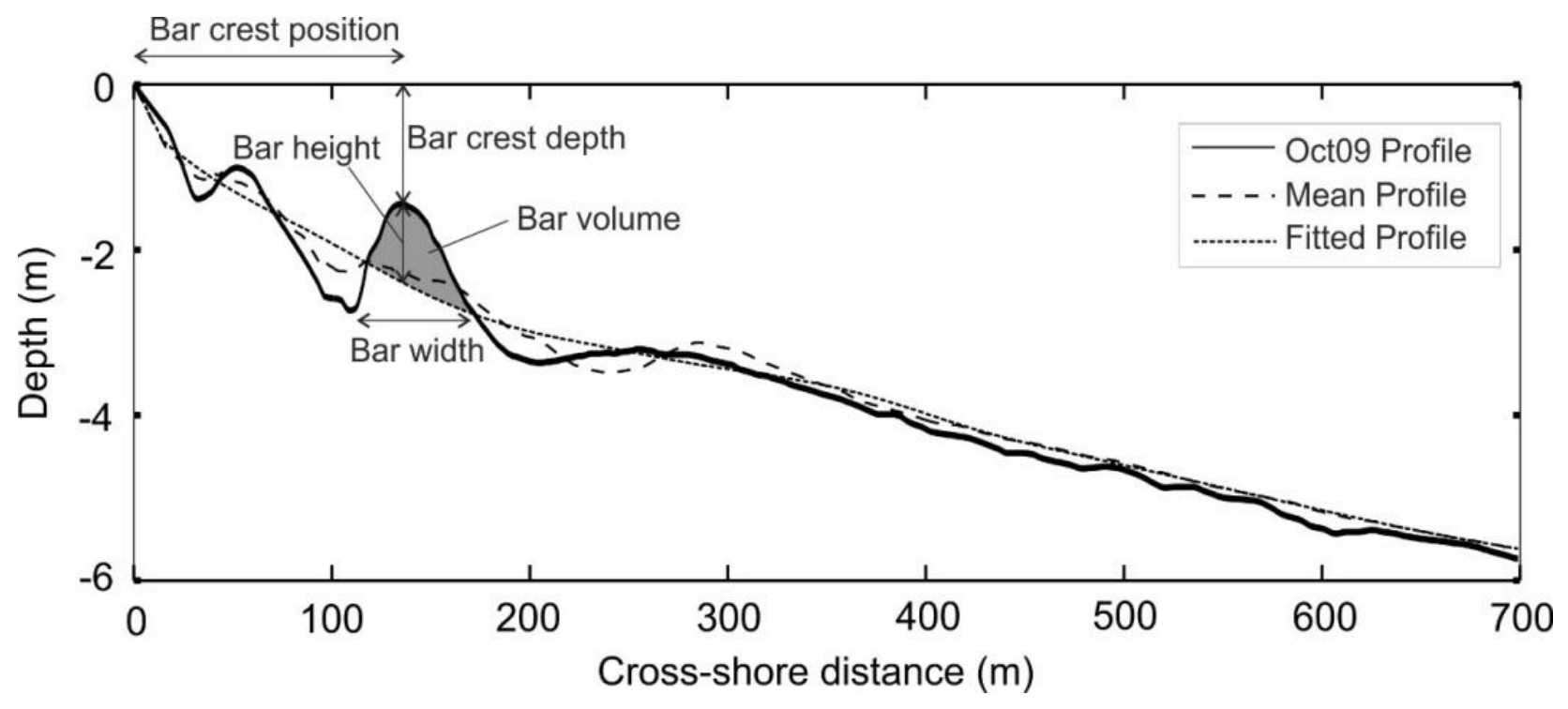

Figure 2 Illustration of sandbar morphometric parameters using P7 profile measured in October 2009

A positive (negative) perturbation corresponds to a sandbar (trough). Shoreline position was extracted for each profile from the seasonal and annual GPS surveys performed in the frame of Sf. Gheorghe Marine and Fluvial Research Station, University of Bucharest. The morphometric parameters were correlated by simple statistical means (Pearson correlation coefficient, significance levels).

\section{Results and Discussions}

\subsection{Correlative dynamics of the sandbar system}

Our analysis focuses on the correlations established between longshore sandbar crest positions and morphology registered at each survey along different sectors of the study site. There is a spatial variability of bar crest positions on Sulina - Sfântu Gheorghe coast between September 2003 and October 2009 under the influence of energetic conditions expressed by mean daily wind speed measured at Sulina meteorological station and mean daily offshore significant wave height obtained from NCEP hindcast data (Fig. 3). We can observe a relative concordance of sandbar movement for both P1 - P7 and P8 - P18 sectors: most of the time they move simultaneously in the same direction - offshore during energetic conditions (e.g. stormy intervals in Fig. 3a,b) and onshore during calm intervals. Sandbars experience a pronounced offshore movement during winter, due to intense storm activity (Vespremeanu-Stroe et al., 2007), as a result of increasing offshore sediment transport during storms caused by wave breaking and powerful undertow currents (Tătui, 2015). 


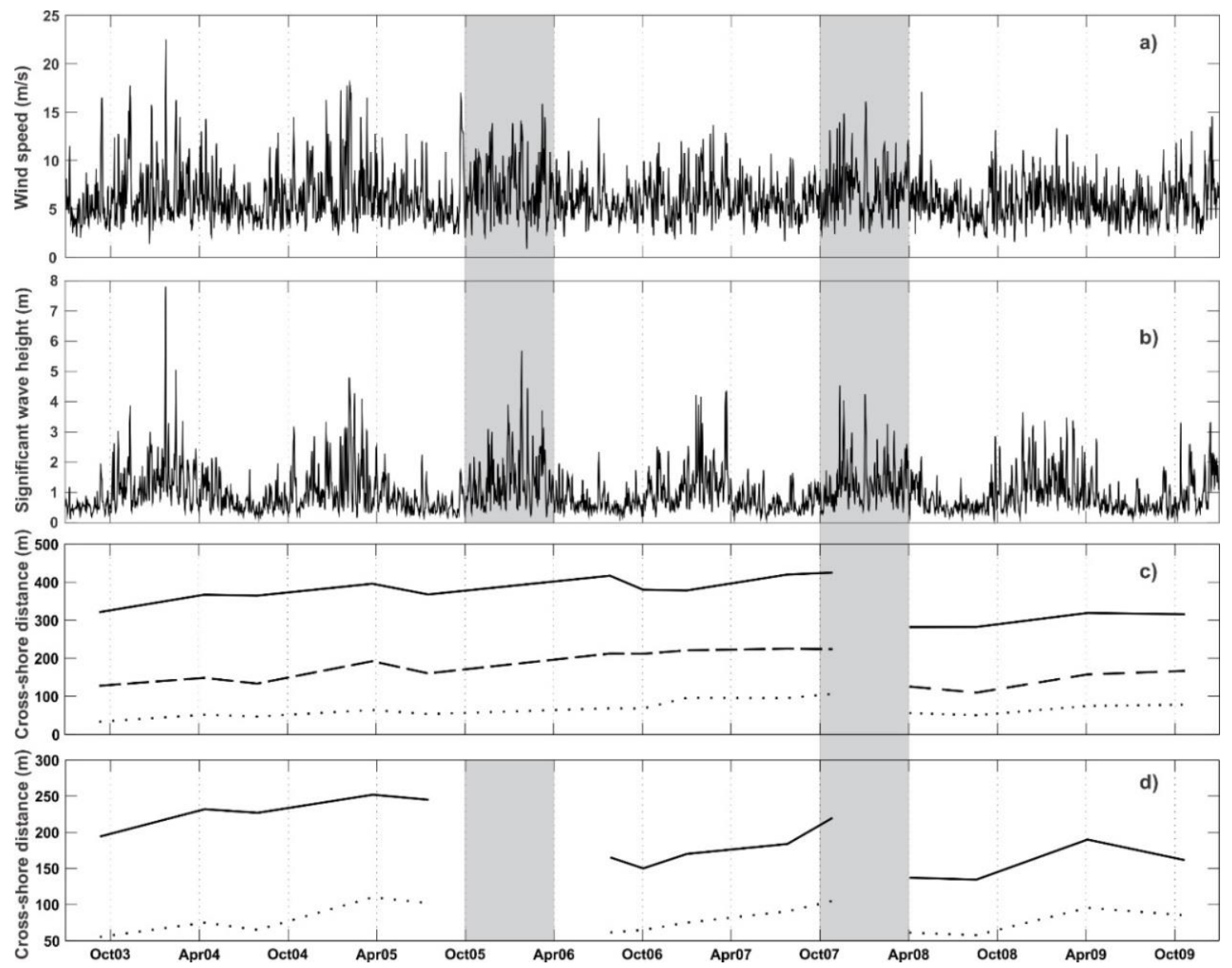

Figure 3 Average bar crest position (outer bar - solid line, middle bar - dashed line, inner bar - dotted line) along (c) P1P7 and (d) P8-P18 sectors versus (a) average daily wind speed measured at Sulina meteorological station and (b) mean daily offshore significant wave height obtained from NCEP hindcast data for an offshore reference point (40 m depth, 18 $\mathrm{km}$ offshore, in front of the Sf. Gheorghe distributary mouth). The grey areas represent the end of a bar migration cycle and the beginning of a new one (time interval when the outer bar disappeared at the offshore limit of the bar zone and a new inner bar formed in shoreline proximity)

During fair weather conditions (summer), sandbars exhibit a moderate/slight onshore movement (Vespremeanu-Stroe et al., 2007) caused by predominant onshore sediment transport due to wave asymmetry during low-energy storms (Tătui, 2015). Overall, the offshore migration rates are higher than onshore ones and, at a multi-annual scale, the sandbars move net offshore in a cyclic manner (Tătui et al., 2016), in a similar way with other sites worldwide: Dutch coast (Ruessink and Kroon, 1994; Wijnberg and Terwindt, 1995); Duck, NC, USA (Plant et al., 1999); New Zealand (Shand and Bailey, 1999); Japan (Kuriyama, 2002); France
(Certain and Barusseau, 2005); consistent with the model proposed by Ruessink and Kroon (1994). From time to time (average cycle return periods ranging from 2.8-3.5 years for the P12 - P18 sector and 4.5-5.0 years for the P3 - P7 area to 5.0-5.5 years for the P1 - P2 sector - Tătui et al., 2016), after continuous movement through the bar zone area (with widths of $250-350 \mathrm{~m}$ on the P8 - P18 sector, 350-450 $\mathrm{m}$ on the P3 - P7 sector and 500-550 $\mathrm{m}$ on the P1-P2 sector - Tătui et al., 2016), the outer sandbar reaches the offshore limit of the bar zone during a stormy interval, causing it to decay and, eventually, disappear (as it was the case in 2005 - 
2006 winter for the P8 - P18 sector and during 2007 - 2008 winter along both P1 - P7 and P8 - P18 sectors - Fig. 3c,d). Its place is immediately taken by the next shoreward located bar and a new bar appears near the shoreline (Fig. $3 c, d$ ), marking the end of an offshore bar migration cycle and the beginning of a new one.
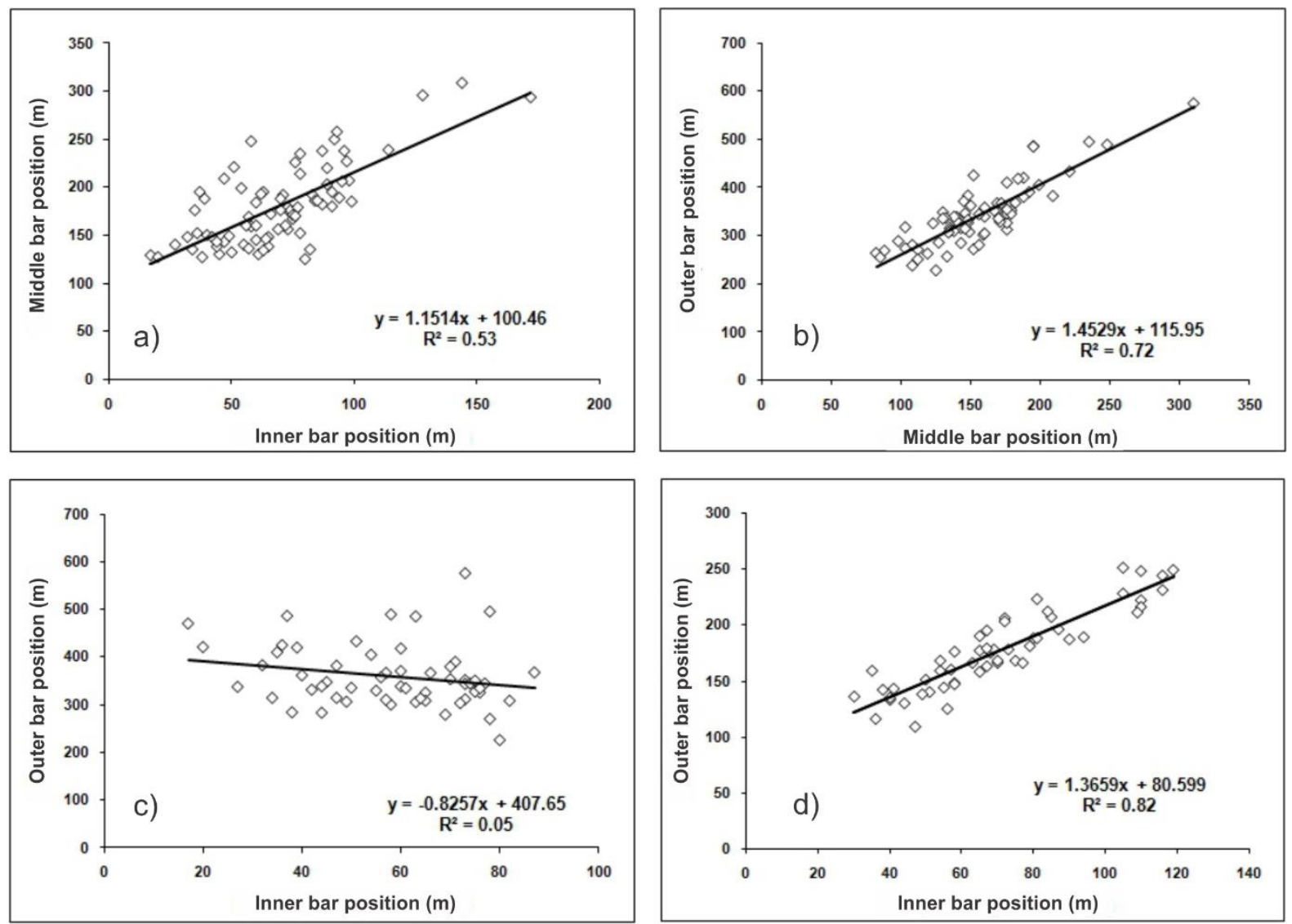

Figure 4 Correlations established between (a) inner and middle sandbars positions; (b) middle and outer sandbars positions and (c) inner and outer sandbars positions along P1 - P7 sector and (d) inner and outer sandbars positions along P8 - P18 sector. Discussion in the text

In order to analyse the longshore and crossshore variability of sandbars correlative behaviour along P1 - P7 sector, we split the three-bar system in two sub-systems: inner one, composed of the inner and middle sandbars (Fig. 4a), and outer one, comprising middle and outer sandbars (Fig. 4b). There is a good positive statistical dependency between inner and middle bar crest positions as $53 \%$ of the inner bar position variability is explained by the middle bar position variability, with a Pearson correlation coefficient of $0.73(p<0.001)$ between the two datasets (Fig. 4a). The positive dependency is more powerful for middle and outer bar crest positions as $72 \%$ of the middle bar position variability is explained by the outer bar position variability, with a Pearson correlation coefficient of $0.85(p<0.001)$, Fig. 4b. The different variance and correlation coefficients values show that the middle bar is more sensitive to the outer bar behaviour and vice-versa in comparison with its relation with the inner bar. The inner bar is very heterogeneous, unstable, mobile and sensitive to the shoreline and lower beach behaviour, so it is trickier to put it in direct relation with middle bar movements. The middle sandbar represents "the bridge" between the two subsystems, moving offshore and onshore and transferring sediment from the inner to the outer bar and the way back. 
At longer time-scales (seasons to years), there is no correlation between the inner and outer bar crest positions (Fig. 4c), showing that, most of the time, the two systems act independently one in relation to the other. For instance, under low to mediumenergy conditions, when the currents are onshore directed as a result of wave asymmetry, the onshore sediment transport is susceptible to be more effective in the inner sub-system to the beach, rather than in the outer sub-system, as the outer bar feels very small to no influence of waves during these energetic conditions due to the high water depth over its crest. With the increasing energy (medium to high conditions), waves could break on the inner and middle sandbar crests and could be asymmetric on the outer bar crest, determining a sediment transport convergence and exchange between the two sub-systems. Under high energy conditions, the two subsystems are both experiencing intense offshore sediment transport as waves break over all sandbars, creating powerful undertow currents. The sediment fluxes are directed from the inner sub-system to the outer sub-system and, sometimes, there is a loss of sediment offshore from the bar zone area (outer sub-system) to the lower shoreface, through bar decay and disappearance, or alongshore, to adjacent areas. During these conditions, the middle and outer sandbars experience the highest correlations between their positions.

Along the double-barred northern erosive P8 P18 sector, there is a strong interdependence between the inner and outer sandbar crests positions (Fig. 4d), expressed by a very strong positive statistical dependency - approximately $82 \%$ of the outer bar position variability is explained by the inner bar position variability, with a Pearson correlation coefficient of $0.9(p<0.001)$. This fact shows a higher coherence of sandbar behaviour along the northern sector in comparison with the southern one, which could be related to the higher nearshore slope and narrower bar zone area (with smaller distance between the two sandbars) which determine synchronous movement (onshore or offshore) of the entire bar system function of the energetic conditions.

Table 1 Correlation coefficients established for the same morphometric parameters between different sandbars along P1 - P7 and P8 - P18 sectors: $B 1$ - inner bar, Bm - middle bar and Bo - outer bar; the values in italics are $95 \%$ statistically significant. Please see explanation in text.

\begin{tabular}{|c|c|c|c|c|c|}
\hline \multirow{2}{*}{$\begin{array}{l}\text { Morphometric } \\
\text { parameter }\end{array}$} & \multicolumn{2}{|c|}{ P1 - P7 Sector } & \multicolumn{3}{|c|}{ P8 - P18 Sector } \\
\hline & $B_{\mathrm{i}} / B_{\mathrm{m}}$ & $B_{\mathrm{m}} / B_{\mathrm{o}}$ & & $B_{\mathrm{i}} / \boldsymbol{B}_{\mathrm{o}}$ & $B_{\mathrm{i}} / B_{\mathrm{o}}$ \\
\hline$P_{\mathrm{c}}$ & 0.73 & & 0.85 & -0.22 & 0.90 \\
\hline$d_{c}$ & 0.39 & & 0.92 & 0.11 & 0.63 \\
\hline$w_{\mathrm{b}}$ & 0.56 & & 0.64 & 0.46 & 0.49 \\
\hline$h_{\mathrm{b}}$ & 0.68 & & 0.50 & 0.26 & -0.10 \\
\hline$V_{b}$ & 0.68 & & 0.57 & 0.35 & 0.24 \\
\hline
\end{tabular}

Furthermore, we computed the correlation coefficients between the main sandbar morphometric parameters (bar crest position - PC and depth $-d c$, bar width $-W b$, height $-h_{\mathrm{b}}$ and volume $-V_{b}$ ) for different sandbar couplings along the two sectors of the study area (Table 1). The highest correlations are registered for sandbar crest position (as we have seen before) - coefficients ranging from 0.73 to 0.9 , with the exception of inner/outer sandbar coupling along P1 - P7 sector (no correlation). Good correlations are also encountered for middle/outer (P1 - P7) and inner/outer (P8 - P18) sandbar depth and for middle/outer (P1 - P7) bar width. Regarding sandbar height and volume, the strongest correlations are registered between inner and middle bars along P1 - P7 sector and are decreasing offshore. The poorest correlations are registered by the inner/outer sandbar coupling along P1 - P7 sector for all morphometric parameters (Table 1).

These correlations imply that, statistically speaking, the two sub-systems are not permanently coupled in their long-term cyclic offshore behaviour. The two sub-systems can behave independently or 
coupled during their seasonal onshore/offshore movement function of the energetic conditions in the surf zone, as we have previously discussed. High energy conditions (storms) are more conducive for the coupling of the two sub-systems, while this coupling is more frequent along P8 - P18 sector for a wider range of energetic conditions in comparison with the P1 - P7 sector.

\subsection{Sandbar system - shoreline correlations}

Researchers tried to establish empirical relations, based on theoretical formulations, laboratory experiments or field measurements, between shoreline mobility and sandbar behaviour. Sunamura and Takeda (1993) investigated the relationships established between the direction of net sandbar migration and shoreline dynamics. Using experimental methods, they established an empirical dimensionless coefficient $A$, defined by the following equation:

$$
\frac{H_{0} \tan \beta}{w_{s} T}=A \frac{w_{s}}{\sqrt{g H_{0}}}
$$

where,

$$
\begin{aligned}
& H_{0}=\text { offshore wave height } \\
& \tan \beta=\text { nearshore slope } \\
& T \quad=\text { wave period } \\
& g \quad=\text { gravitational constant } \\
& w_{s}=\text { sediment fall velocity }, \text { defined by: } \\
& \qquad w_{s}=\frac{(s-1) g d_{50}^{2}}{18 v}
\end{aligned}
$$

in which,

$s=$ relative density, expressed by $\rho_{s} / \rho=2650$ $\mathrm{kg} / \mathrm{m}^{3} / 1000 \mathrm{~kg} / \mathrm{m}^{3}=2.65$

$d_{50}=$ median particle size

$v \quad=$ kinematic viscosity $=10^{-6}$

Using $L_{0}=g T^{2} / 2 \pi$, equation 1 transforms in:

$$
A=\left(\frac{1}{\sqrt{2 \pi}}\right)\left(\frac{w_{s}}{\sqrt{g H_{0}}}\right)^{-2}\left(\frac{H_{0}}{L_{0}}\right) \xi_{0}
$$

(3)

where,

$L_{0}=$ offshore wave length $\xi_{0}=$ surf similarity parameter, defined by:

$$
\xi_{0}=\tan \beta / \sqrt{H_{0} / L_{0}}
$$

(4)

Equation 3 indicates that parameter $A$ has three components:

i) Wave-sediment parameter $=w_{s} / \sqrt{g H_{0}}$ ；

ii) Wave steepness $=H_{d} / L_{0}$,

iii) Wave-topography parameter $=\xi_{0}$.

Based on experiments conducted in large wave flumes, Sunamura and Takeda (1993) found the following relations:

a) if $A \geq 14$, sandbars migrate offshore and shoreline retreats;

b) if $A \leq 3.5$, sandbars migrate onshore and shoreline advances;

c) if $3.5<A<14$, sandbars migrate offshore and shoreline is stable or advances.

After applying these formulations to field measurements, they adjusted the value of $A$ from 14 to 17 .

Based on the above described methodology, we computed the values of $A$ (taking into consideration a threshold value of 14 , which we consider more suitable for dissipative and intermediate beaches, as it is our case) for the southern (P1 - P7) and northern (P8 - P18) sectors of our study site, in different energetic conditions, using the following inputs:

$>H_{0}, T_{0}=$ lacking in-situ measurements of wave height and period along the study site and adjacent coasts, we have included in the computations the mean values of $H_{0}$ and $T_{0}$ obtained by Vespremeanu-Stroe (2007) using theoretical formulations. Despite small differences regarding offshore wave height and period between the two sectors, we have considered in our analysis similar values of the two parameters;

$>\tan \beta=$ the upper shoreface slope has a longshore variability along the study area (Tătui and Vespremeanu-Stroe, 2016). In our computations, we have used the mean values of $\tan \beta$ for the barred area: 0.0065 (for the southern sector) and 0.0085 (for the northern sector); 
$>w_{s}=$ depends on $d_{50}$. As there are very small alongshore differences in $d_{50}$ values (Preoteasa and Vespremeanu-Stroe, 2010) along the study site, we have considered a constant value of 0.2 $\mathrm{mm}$ for the two sectors.

Analysing the above presented methodology and parameters and assuming that, at larger timescales (years, decades), the wave climate and sediment characteristics do not register major differences between the two sectors, we can conclude that two (wave-sediment parameter and wave steepness) of the three components of coefficient $A$ are constant along Sulina - Sfântu Gheorghe coast. The only component that registers significant longshore variability is the wavetopography parameter, which is mainly influenced by the nearshore slope: even if the offshore waves do not show significant differences between the two sectors, the higher slope along the northern sector imposes larger wave breaking on sandbars crests and, hence, more powerful undertow currents which determine faster sandbars offshore movement (Tătui et al., 2016) and, eventually, shoreline erosion. The analysis of coefficient $A$ values function of the energetic (wave) conditions of the study area resulted in the identification of five cases with different sandbars and shoreline behaviour along the two sectors (Table 2). In all cases parameter $A$ values are higher along the northern sector (P8 $\mathrm{P} 18)$ in comparison with the southern one (P1 - P7) because of the higher nearshore slopes which determine larger waves and more powerful currents (especially undertow) along the first sector during the same energetic conditions.

Table 2 The values obtained for parameter $A$ for different energetic conditions along the study site.

\begin{tabular}{cccccc}
\hline & \multirow{2}{*}{ Frequency (\%) } & \multicolumn{2}{c}{ Energetic conditions } & \multicolumn{2}{c}{ Parameter $\boldsymbol{A}$} \\
\cline { 3 - 5 } & & $\boldsymbol{H}_{\boldsymbol{s}, \boldsymbol{O}}(\mathbf{m})$ & $\boldsymbol{T}_{\boldsymbol{o}}(\mathbf{s})$ & Sect. P1 - P7 & Sect. P8 - P18 \\
\hline Case 1 & 0.7 & $>3.85$ & $\geq 8.4$ & $>14$ & $>14$ \\
Case 2 & 0.3 & $3.2-3.85$ & 8.4 & $3.5-14$ & $>14$ \\
Case 3 & 13 & $1.3-3.2$ & $6.5-8.4$ & $3.5-14$ & $3.5-14$ \\
Case 4 & 8.5 & $1.1-1.3$ & 6.5 & $<3.5$ & $3.5-14$ \\
Case 5 & 77.5 & $<1.1$ & $<6.5$ & $<3.5$ & $<3.5$ \\
\hline
\end{tabular}

Low-energy waves (case 5), which have the highest frequency during the year (but lowest morphological impact), create conducive conditions for shoreline progradation and onshore sandbars movement. During these conditions, the inner sandbar is placed very close to the shoreline and the sediment transport is oriented onshore. Under longlasting low-energy conditions, the inner bar splits its crest in a ridge, which maintains its relative position, and in a moving body of sand which fills the innermost through (the area between the shoreline and the inner bar), transforming it in a sort of platform and, eventually, attaching to the sub-aerial berm. This is the main mechanism of shoreline progradation along the study site and these type of processes and behaviour were first documented by Vespremeanu-Stroe (2001, 2007) through field measurements of the shoreline - inner bar area.

During medium-energy conditions (case 4 and, especially, case 3 ), which account for almost $25 \%$ of the year, an important part of sediment is transported offshore by undertow currents which determine offshore movement of the inner and middle sandbars. This mechanism takes place under lower energy conditions along the northern sector due to the higher nearshore slopes. A small part of the sediment transport is still onshore oriented, feeding the inner bar and the berms and maintaining the shoreline stable or slightly advancing. This is mainly the case of the southern sector which benefits from higher sediment budgets in the proximity of the Sf. Gheorghe river mouth. One of the main causes of this different behaviour of the sandbars - shoreline system during mediumenergy condition could be related to the fact that the same waves could be characterised by asymmetry (which favours onshore

sediment transport) along the southern sector and by breaking (which determine the formation of undertow currents responsible for offshore 
sediment transport) along the northern sector, as a results of the differences in nearshore slope. Further investigation is needed in order to document these differences in wave characteristics under mediumenergy conditions along the two areas of the study site.

High waves (case 2 and, especially, case 1) during intense storms determine wave breaking on sandbars crests and the formation of undertow currents which are responsible for offshore sediment transport and, hence, for shoreline retreat, beach erosion and offshore sandbars movement. Lower waves (case 2) determine the shoreline to erode and the sandbars to move offshore along the northern sector in comparison to the southern one, where higher waves (case 1) make this possible. This is related to the larger nearshore slope and narrower bar zone area (265 $\mathrm{m}$ on average) along the northern sector, which allows intense wave breaking on inner and outer sandbars; still, the wave energy is not entirely dissipated and part of this energy reaches the shoreline determining beach erosion and shoreline retreat. Along the southern sector, the wide bar zone area (505 $\mathrm{m}$ on average) assures sufficient space for wave dissipation (breaking on inner, middle and, eventually, outer sandbars and reformation in the troughs) during case 2 energetic conditions, protecting the beach against wave attack and erosion (the shoreline is stable).

The predicted short-term (days to seasons) behaviour of shoreline and sandbars (obtained using the methodology developed by Sunamura and Takeda, 1993) for different energetic conditions show good correspondence with the nearshore dynamics and processes observed along the study area. This methodology is able to offer valuable information regarding the immediate response of sandbars and shoreline to changing energetic conditions. Still, the established thresholds should be treated cautiously because these empirical mathematical relations are based mainly on flume experiments, without being properly validated with field measurements.

At longer time scales (years), the analysis of the cross-shore profiles (from waterline to depth of closure) show very good agreement between the multi-annual shoreline behaviour and sandbar movement along Sulina - Sf. Gheorghe interdistributary coast (Fig. 5).

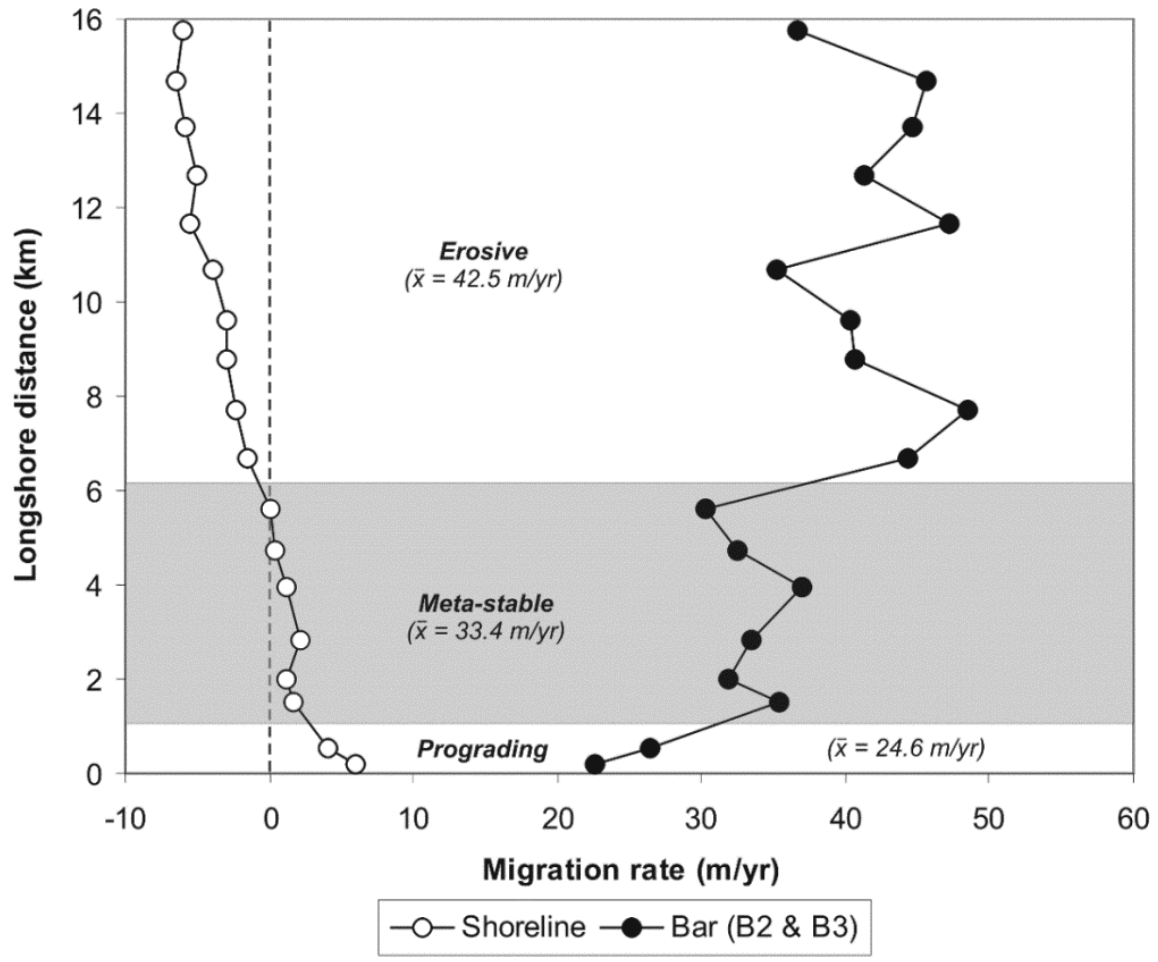

Figure 5 Shoreline dynamics versus sandbars offshore migration rates along Sulina - Sf. Gheorghe beaches (2003-2009) 
The multi-decadal shoreline dynamics is characterised by gradually decreasing downdrift (from North to South) erosional processes along the northern sector: average retreat rates ranging from $7.5 \mathrm{~m} / \mathrm{yr}$ at $\mathrm{km} 16$ (P18) to $1.8 \mathrm{~m} / \mathrm{yr}$ at $\mathrm{km} 6$ (P8) between 1979 and 2009. The stable central sector (P3 - P7 / km 1 to 6 northward of Sf. Gheorghe river mouth) shows a meta-stable shoreline equilibrium since the beginning of the 20th century, while the southern sector (P1 - P2 / km 0 to 1) registered average shoreline advance rates of $1-2 \mathrm{~m} / \mathrm{yr}$ between 2003 and 2009 (Vespremeanu-Stroe et al., 2007; Tătui et al., 2013). The latter sector is highly influenced by the presence and dynamics of the river mouth bar which controls the sedimentary fluxes and wave characteristics (Tătui et al., 2016).

The multi-annual cyclic offshore sandbar behaviour is closely related to the long-term shoreline evolution, the sandbar migration rates increasing progressively from accumulative to erosive conditions along the study area (Fig. 5). The accumulative sector is characterised by the lowest sandbar migration rates $(20-30 \mathrm{~m} / \mathrm{yr})$; along the stable sector, the sandbars migrate offshore with mean rates between 30 and $37 \mathrm{~m} / \mathrm{yr}$; the erosive sector registers the highest offshore sandbar migration rates of $40-50 \mathrm{~m} / \mathrm{yr}$. These connections between shoreline and sandbar behaviour are related to the controlling factors (nearshore slope and sediment availability) which determine different hydrodynamic conditions, sediment dynamics and morphology along different sectors of the study site.

\section{Conclusions}

The upper shoreface profile of the interdistributary Sulina-Sf. Gheorghe deltaic coast shows significant correlations established between longshore sandbar crest positions and morphology. These connections involve sedimentary exchange between neighbouring sandbars and, under certain conditions, simultaneous movement in the same direction (onshore, during low-energy conditions or offshore, during high-energy events). Along the three-bar system of the central and southern sectors, the two sub-systems (inner one, composed of inner and middle sandbars and outer one, composed of middle and outer sandbars) act more or less individually, the middle bar movement and associated sediment transfer being the linkage between them. High-energy conditions are conducive for the most intense interactions between the two sub-systems. The coupling between the inner and outer sandbar sub-systems is more frequent during a wider range of energetic conditions (from low/medium- to high-energy) along the northern erosive sector in comparison with the southern/central accumulative/stable ones (where only the medium/high-energy events drive this coupling).

The methodology developed by Sunamura and Takeda (1993) predicted reasonably well the shoreline behaviour and the direction of sandbars movement observed for different energetic conditions along the study site, even if the established thresholds should be used cautiously. Nevertheless, there is an obvious connection between the long-term shoreline mobility and sandbars offshore migration rates along different sectors of the study area. The lowest sandbar migration rates (with associated longer cycle return periods) occur on the prograding sector, while the fastest sandbar movement (with associated shorter cycle return periods) registers on the retreating sector. Parameter $A$ analysis helped us to validate our previous findings (Tătui et al., 2016) stating that, along the study site, the main driver of the relationship between long-term sandbars dynamics and shoreline variability is represented by the longshore variations of the nearshore slope.

\section{Acknowledgements}

The presented analyses were undertaken in the frame of the strategic grants POSDRU/159/ $1.5 / S / 133391$ and POSDRU/6/1.5/S/24. Part of the research activities were funded by the Romanian Organization for Scientific Research (CCCDIUEFISCDI) through grants ERANET 42 and CAPACITATI 792, under PNCDI III. Dr. Alfred Vespremeanu-Stroe is highly acknowledged for 
fruitful discussions and for the idea of performing the analysis related to Fig. 5. Field surveys were carried out in the frame of Sf. Gheorghe Marine and Fluvial Research Station, Faculty of Geography, University of Bucharest.

\section{References}

Almar R, Castelle B, Ruessink BG, Sénéchal N, Bonneton $P$, Marieu V. 2010. Two- and three-dimensional doublesandbar system behaviour under intense wave forcing and a meso-macro tidal range. Continental Shelf Research 30: 781-792.

Bowman D, Goldsmith V. 1983. Bar morphology of dissipative beaches: an empirical model. Marine Geology 51: 15-33.

Castelle B, Bonneton P, Dupuis H, Sénéchal N. 2007. Double bar beach dynamics on the high-energy meso-macrotidal French Aquitanian Coast: A review. Marine Geology 245: 141-159.

Castelle B, Ruessink BG, Bonneton P, Marieu V, Bruneau N, Price TD. 2010. Coupling mechanisms in double sandbar systems. Part 1: Patterns and physical explanation. Earth Surface Processes and Landforms 35: 476-486.

Certain R, Barusseau J-P. 2005. Conceptual modelling of sand bars morphodynamics for a microtidal beach (Sete, France). Bulletin de la Société Géologique de France 176(4): 343-354.

Coco G, Bryan KR, Green MO, Ruessink BG, Turner IL. 2005. Video observations of shoreline and sandbar coupled dynamics. In: Proceedings of Coasts and Ports 2005, 471-476.

GEOECOMAR 1995. Sedimentology and bathymetric map of the Black Sea continental shelf-Sulina Sheet.

Gervais M, Balouin Y, Certain R. 2013. The major control parameters of storm morphological evolution on a microtidal barred beach. In: Proceedings of Coastal Dynamics 2013, 725-736.

Grunnet NM, Hoekstra P. 2004. Alongshore variability of the multiple barred coast of Terschelling, The Netherlands. Marine Geology 203: 23-41.

Hom-ma M, Sonu C. 1962. Rhythmic pattern of longshore bars related to sediment characteristics. In: Proceedings of 8th Internat. Conference on Coastal Engineering ASCE: New York 248-278.

Kuriyama Y. 2002. Medium-term bar behavior and associated sediment transport at Hasaki, Japan. Journal of Geophysical Research 107(C9), 15-1-15-12.

Plant N, Holman R, Freilich M, Birkemeier W. 1999. A simple model for interannual sandbar behavior.
Journal of Geophysical Research 104(560): 15755-15776.

Preoteasa L, Vespremeanu-Stroe A. 2010. Grain-size analysis of the Beach-dune sediments and the geomorphological significance, Revista de Geomorfologie 12: 73-79.

Price TD, Rutten J, Ruessink BG. 2011. Coupled behaviour within a double sandbar system. Journal of Coastal Research SI 64 (Proceedings of the 11th International Coastal Symposium) 125-129. Szczecin, Poland.

Price TD, Ruessink BG. 2013. Observations and conceptual modelling of morphological coupling in a double sandbar system. Earth Surf. Process. Landforms 38: 477-489. doi:10.1002/esp.3293.

Price TD, Ruessink BG, Castelle B. 2014. Morphological coupling in multiple sandbar systems - a review, Earth Surface Dynamics 2: 309-321.

Quartel S. 2009. Temporal and spatial behaviour of rip channels in a multiple-barred coastal system. Earth Surface Processes and Landforms 34: 163-176.

Rozynski G. 2003. Data driven modelling of multiple longshore bars and their interactions. Coastal Engineering 48: 151-170.

Ruessink BG, Kroon A, 1994. The behaviour of a multiple bar system in the nearshore zone of Terschelling, The Netherlands: 1965-1993. Marine Geology 121: 187-197.

Ruessink BG, Wijnberg KM, Holman RA, Kuriyama Y, van Enckevort IMJ. 2003. Intersite comparison of interannual nearshore bar behavior. Journal of Geophysical Research 108: 5-3, 5-12.

Ruessink BG, Coco G, Ranasinghe R, Turner IL. 2007. Coupled and noncoupled behavior of threedimensional morphological patterns in a double sandbar system. Journal of Geophysical Research 112: C07002, DOI: $10.1029 / 2006$ JC003799.

Shand R, Bailey D. 1999. A review of net offshore bar migration with photographic illustrations from Wanganui, New Zealand. Journal of Coastal Research 15: 365-378.

Short AD. 1999. Handbook of beach and shoreface morphodynamics. Wiley: Chichester, UK.

Sonu CJ. 1973. Three-dimensional beach changes. Journal of Geology 81: 42-64.

Sunamura T, Takeda I. 1993. Bar movement and shoreline change: predictive relations. Journal of Coastal Research SI 15: 125-140.

Tătui F, Vespremeanu-Stroe A, Ruessink BG. 2011. Intrasite differences in nearshore bar behavior on a nontidal beach (Sulina-Sf. Gheorghe, Danube Delta coast). Journal of Coastal Research SI 64: 873-878.

Tătui F, Vespremeanu-Stroe A, Preoteasa L. 2013. The correlated behavior of sandbars and foredunes on a nontidal coast (Danube Delta, Romania). In: Conley 
DC, Masselink G, Russell PE, O'Hare TJ. (eds.). Proceedings 12th International Coastal Symposium (Plymouth, England). Journal of Coastal Research SI 65: 1874-1879.

Tătui F. 2015. Nearshore Sandbar Behavior on Danube Delta Coast (in Romanian). University of Bucharest. $\mathrm{PhD}$ thesis.

Tătui F, Vespremeanu-Stroe A, Ruessink BG. 2016. Alongshore variability of cross-shore bar behavior on a nontidal beach. Earth Surface Processes and Landforms DOI: 10.1002/esp.3974.

Tătui F, Vespremeanu-Stroe A. 2016. Evolution and morphodynamics of Danube Delta shoreface, In: Rădoane M, Vespremeanu-Stroe A. (eds.) Landform Dynamics and Evolution in Romania, 607-626, Springer Geography.

Thornton EB, MacMahan JH, Sallenger AH Jr. 2007. Rip currents, mega-cusps, and eroding dunes. Marine Geology 240: 151-167.

Van Enckevort IMJ, Wijnberg KM. 1999. Intra-annual changes in bar plan shape in a triple bar system. In: Proceedings of Coastal Sediments '99, 2548-2558.
Van de Lageweg WI, Bryan KR, Coco G, Ruessink BG. 2013. Observations of shoreline-sandbar coupling on an embayed beach, Marine Geology 344: 101-114.

Vespremeanu-Stroe A. 2001. Morfodinamica avanplajei din cadrul tarmului Sfantu Gheorghe. Revista de geomorfologie 3: 141-148.

Vespremeanu-Stroe A. 2007. Tărmul Deltei Dunării. Studiu de geomorfologie. University of Bucharest. PhD thesis.

Vespremeanu-Stroe A, Constantinescu Ş, Tătui F. 2007. Comportamentul multianual al barelor submerse pe coasta Deltei Dunarii. Revista de Geomorfologie 9: 107-123.

Wijnberg KM, Terwindt JHJ. 1995. Extracting decadal morphological behaviour from high-resolution, longterm bathymetric surveys along the Holland coast using eigenfunction analysis. Marine Geology 126: 301-330. 